\title{
Toward A Broader - But Still Rigorous - Definition Of Leader Integrity: \\ Commentary
}

\section{Tony Simons}

School of Hotel Administration, Cornell University, Ithaca Nyu 14853 E 25th St - 6902, New York, NY 10010-2545

Corresponding author.

E-mail address: Tony.simons@cornell.edu.

\section{Michael Palanski}

College of Business, Rochester Institute of Technology, 108 Lomb memorial Drive, Rochester, NY 14623-5608

E-mail address: mpalanski@saunders.rit.edu.

\section{Linda Treviño}

Smeal College of Business, Pennsylvania State University, 411 Business Building, University Park, PA 16802-3005

E-mail address: 1trevino@psu.edu.

\section{Background for special issue}

The impetus for this special issue of The Leadership Quarterly grew out of the desire of a small but enthusiastic group of leadership scholars who were interested in the concepts of integrity in general and behavioral integrity (the consistency between words and actions) in particular. Guest Editor Tony Simons' (2002) theoretical article in Organization Science had sparked a great deal of interest in behavioral integrity, including the interest of a then-doctoral student at Binghamton University, Guest Editor Mike Palanski. Palanski was seeking advice for his dissertation, and Simons wished to build a cadre of scholars with an interest in leader behavioral integrity. A year or so later, Palanski had the "misfortune" of presenting a paper on 
integrity as the final presenter in the final session on the final day of the 2006 Academy of Management conference in Atlanta. To his surprise, the room was packed, and it quickly became clear that others also wished to study leader integrity in more depth.

Most of the previous research had focused on behavioral integrity. The Journal of Applied Psychology published two early articles on behavioral integrity (Dineen, Lewicki, \& Tomlinson, 2006; Simons, Liu, Friedman, \& Parks, 2007) and Simons began to organize 1-2 symposia on behavioral integrity each year at the Academy of Management conferences. As momentum increased, behavioral integrity began to emerge as a relatively simple and "clean" construct that had significant explanatory power. However, behavioral integrity is strictly speaking an amoral construct; in otherwords, it focuses on consistency betweenwords and actions without regard to the content of the words and actions. Thus, the answer to the wearisome question, "Did Hitler have behavioral integrity?" is essentially yes. While perhaps not satisfying, this view allowed behavioral integrity to mostly escape endless debate about morality and proceed to empirical testing - and demonstrated practical usefulness. Yet, there continued to be a sense that perhaps something was missing because the common understanding of integrity includes the idea of moral or ethical behavior.

In the desire to revisit this aspect of integrity, and to push nascent work on behavioral integrity even further, the idea of a special issue was born. Senior Leadership Quarterly Editor Leanne Atwater was very supportive of the idea, and suggested that Tony and Mike seek someone with a somewhat broader perspective to assist in the editing process. We were honored to have Linda Treviño join as the third guest editor, as Linda's extensive work on ethical leadership is a natural complement to leader integrity. In all, five papers made it into the Special Issue. Each of them serves to push the frontier of leader integrity research, and four of them 
broaden the conceptualization of leader integrity beyond word/action consistency. It was a pleasure to guest edit these articles and we hope that you benefit from reading them.

\section{Overview}

The five papers in this special issue advance the study of leader integrity by refining construct definition and measurement, and by demonstrating the performance implications of leader integrity. These papers build on the foundation of behavioral integrity research and four of the five papers highlight and respond to the common understanding that leader integrity incorporates a moral component. Thus, a key collective contribution of these papers is a better integration of morality into leader integrity research.

- Bauman reviews historical, philosophical and business discussions of integrity, and argues that morality, in addition to consistent adherence and follow-through, is a fundamental element of all of them. He then proposes three different types of leader integrity. All contain consistent adherence and follow-through, but the three differ in the morality, immorality, or neutrality of the adhered-to values.

- Martin and colleagues query respondents in six different countries about the meaning of leader integrity - they find evidence of convergence around alignment and morality, but also differences in emphasis and meaning across cultures.

- Moorman and colleagues develop a two-dimensional survey measure of leader integrity, comprising dimensions of consistency (behavioral integrity) and morality. They 
demonstrate that the two dimensions predict unique variance in trust, and that they affect other job attitudes through the mediation of trust.

- Vogelgesang and colleagues apply the behavioral integrity construct to platoons of military cadets using longitudinal, multilevel data. They find that leaders' communication openness predicts cadets' perceptions of the behavioral integrity of their leader, which in turn predicts cadets' engagement, which predicts their military grade performance.

- Gentry and colleagues study leader integrity in middle managers as well as senior executives. They apply a measure of leader integrity that combines both morality and consistency dimensions, and find that leader integrity predicts performance, but not as strongly as it does for senior managers. Other character strengths such as social intelligence are more important for predicting middle manager performance.

In sum, this series of papers enhances our collective understanding of leadership integrity by enhancing our understanding of the concept and our measurement of it, and by further validating its empirical usefulness as a driver of attitudes and performance. Specific points regarding each paper:

\section{Bauman}

Bauman reviews historical, philosophical, and business-related uses of the term integrity to demonstrate that common usage of the word integrity denotes some form of moral action. $\mathrm{He}$ then proposes that moral integrity must include "identity-conferring commitments." This is a unique perspective on one of the enduring questions surrounding integrity; namely, to what 
extent is integrity about acting in accordance with one's internal values and to what extent is it about acting in accordance with one's stated values? Bauman argues that true integrity consists of commitment to values that are so deeply held that they form one's identity and self-concept. To violate one's own integrity would be an identity-jarring occurrence because integrity is not adherence to trivial values, or even to important values, but indeed to fundamental, "this is who I am at my core" values.

Bauman builds on this foundational idea of integrity as identity-conferring values to posit three different faces (types) of integrity. Substantive integrity is commitment to moral identityconferring values; that is, values that are universally acknowledged to support human flourishing. Formal integrity is commitment to immoral identity-conferring values; that is, values which impede the development of a moral community. Personal integrity is commitment to personal identity-conferring values; that is, values that a particular person has deemed essential to his or her self-concept, but also values that, if they were to change, would not damage the moral community per se.

Bauman's model is useful in two ways. First, by introducing the idea of integrity as identity-conferring commitments, it provides a tool for distinguishing between trivial and nontrivial matters. Therefore the person who prefers butter but decides to cook with margarine is not in danger of damaged integrity, but the person who values honesty and deliberately lies to cover up a scandal is in such danger. Second, by positing the three faces of integrity, it provides a tool for categorizing moral, immoral, and (to some extent) amoral versions of integrity.

This approach is useful in pointing out that consistency is a virtue when applied to moral values, but possibly not when applied to immoral or amoral ones. However, while there may be some universally shared moral principles, there appears also to be some cultural component to 
the judgment of morality and immorality — as witnessed by the Martin et al. paper in this volume, or by the extreme polarization and apparent mutual moral condemnation of the two dominant parties ("tribes"?) in the US political system (Graham, Haidt \& Nosek, 2009). Thus, this work could be built upon by more fully considering the role of the subjective observer, and of culture, in determining integrity and its consequences.

\section{Martin, Keating, Resick, Kwan, Szabo \& Peng}

Martin and colleagues perform a content analysis that compares the meaning of leader integrity in six societies that the authors grouped into three clusters, an Anglo cluster (Ireland and the US), a Germanic cluster (Germany and Austria), and a Confucian Asian cluster (China

and Hong Kong). The authors interview managers from each culture in order to understand their beliefs about and understanding of leader integrity. Based upon content analysis of the interviews, the authors conclude that definitions of leader integrity across countries overlap substantially. For example, values-based behavior is an attribute of leader integrity across all societies, as are word-action consistency, fairness, consideration and honesty. But managers also differ across countries. Managers from some countries include a sense of social responsibility, kindness and/or caring for others as part of the leader integrity definition; others include following regulations; yet others include traits of openness, egalitarianism ("non-hierarchical") and selflessness.

In sum, while these preliminary qualitative results would benefit from replication and refinement, they point a way toward understanding different expectations and ideals for leadership across cultures. While battles over the proper single definition for the term, "leader 
integrity" might not be fruitful, it is useful to understand how different populations understand the term, and to understand also how they determine which leaders are most worthy of their followership. This work should help to provide direction to future cross-cultural research in leader integrity.

\section{Moorman, Darnold, and Priesemuth}

This paper addresses an ongoing tension around behavioral integrity, which some argue is "incomplete" because it does not include morality. Clearly, most understand something more than simply consistency when they describe or call for leader integrity. This paper distinguishes morality and consistency as two dimensions of leader integrity. It draws upon diverse philosophic approaches to morality to develop scale items, and then demonstrates how moral integrity and behavioral integrity each account for unique variance in follower attitudes, as mediated by trust.

A few questions emerge from the proposed multidimensional conceptualization of leader integrity. What role, for example, does perceived value congruence play in the assessment of morality as measured in this fashion? How do the two proposed dimensions interact—is consistency a plus when I see you as moral, but a minus when I do not? What determines strength of association between dimensions - under what circumstances do they diverge?

The measure proposed here may become a dominant instrument in future leader integrity research - at least one of the guest editors plans to use it.

\section{Vogelgesang, Leroy, and Avolio}


These authors use multi-source time-lagged data from a military academy to demonstrate the considerable predictive power of leader behavioral integrity. Their study shows that leader transparent communication at time one predicts work engagement at time two, a relationship that is mediated by leader behavioral integrity. Follower engagement is also related to follower performance at time 3 . The predictive power of leader behavioral integrity is striking in this study as it is comparable to that of much broader constructs such as justice and transformational leadership. This research also further articulates the link between behavioral integrity and authentic leadership, as transparency is a component of authentic leadership. As such it builds upon the broader links proposed and tested in Leroy, Palanski and Simons (2012). Another exciting contribution of this piece is that it tests worker engagement as a consequence of leader behavioral integrity that mediates links to performance. This link was proposed in Simons (2008) but had not yet been shown in published research.

\section{Gentry, Cullen, Sosik, Chun, Leupold, and Tonidandel}

This paper offers a perspective on leader integrity that is embedded in the character strength and virtue literature. These authors describe leader integrity as a builder of social capital, typically in the form of trust.

The survey scale used to measure leader integrity is a proprietary one that combines questions that tap into both moral and behavioral integrity-thus the measure pools the two with an unknown weighting assigned to each. Despite this limitation in terms of unspecified 
weighting and availability to other scholars, it seems to capture the common definition of leader integrity and demonstrates good statistical reliability.

The study found, for a sample of middle managers, that leader integrity predicts performance, but that this impact is less potent as a performance driver than is social intelligence. For more senior managers examined in previous studies, leader integrity was found to be more important. The authors suggest that these results mean we should spend more time building and assessing integrity for middle managers. While we would agree with the recommendation as an implication of the data and a good idea in general, it is also true that studies of relative impact may be affected by instrumentation and the particular work context studied. Still, the findings make intuitive sense and, if they hold up in future work they will have significant implications for leader selection and development processes.

This study adds to the mounting evidence showing that leader integrity, as broadly or narrowly defined, affects manager and executive performance. This pattern of results is part of what gives leader integrity research so profound a potential impact on management practice: Powerful performance results resonate with audiences who might not be moved by any inherent value of integrity or honor. In this way, leader integrity research has the potential to reach, and thus to affect the long-term behavior of aspiring and current business leaders. The message is likely to resonate not only with those already positively inclined toward ethical behavior, but more critically, to reach those who are more Machiavellian in their pursuit of superior performance. The more firmly we can establish the performance consequences of leader integrity, the more we believe we will be able to enhance the ethical conduct of business through the integrity of its leaders. 


\section{Directions for further research}

Leader integrity continues to represent a very promising and relatively under-explored research stream that is intuitively appealing. While initial studies of its consequences have demonstrated strong practical importance of the concept, many questions remain unanswered regarding measurement, the breadth of its applicability, the integration of the construct into the nomological network, further articulation of its causes, theoretical underpinnings, and consequences, and, ultimately, the development and testing of practical interventions.

We propose that the science needs to more fully embrace a consensus understanding of the nature of leader integrity, and more fully clarify the nomological network by articulating and measuring the relationships among leader integrity and, for example, authentic leadership, ethical leadership, and charismatic leadership. For example, does leader integrity predict outcomes above and beyond these existing constructs? What are the underlying theoretical mechanisms, if any, beyond trust? If leader integrity is multidimensional, how are the different dimensions weighted in terms of their effects?

We need also to consider more deeply the role of follower characteristics, expectations and values in the above processes and relationships. For example, Martin and colleagues' piece points toward a need for better understanding of the differing roles and expectations regarding leader integrity across cultures.

Moorman's article presents an interesting twist on Mayer, Davis, and Schoorman's (1995) framework of ability, benevolence and integrity as three primary trust drivers: If, as Moorman finds, leader integrity represents two distinct elements, these should be distinguished and tested as part of a larger picture of the drivers of trust in leaders. Is the "morality" element of integrity 
best conceived as an absolute, or as value congruence? If the latter, can it be empirically differentiated from benevolence?

It is interesting also to consider more fully the mechanisms by which integrity operatesis the impact only through trust? Simons (2008) proposed that integrity also operates through communication clarity as integral, well-aligned messages are less ambiguous than are hypocritical ones. Are there additional mechanisms of impact as well?

One particularly fruitful direction in the study of leader integrity may be the notion of behavioral integrity as a moderator of other leader behaviors that may be effective only when performed by a credible leader. For example, Dineen et al. (2006) found that leader coaching backfires absent behavioral integrity. Similar relationships might be expected for change initiatives and other leadership actions.

A further under-explored area is articulating and examining the impact of situational factors on leader integrity. How do incentives, resource constraints, peer climates and other factors influence demonstrated leader integrity. Understanding situational and contextual influences will allow us to design high-integrity workplaces and high-integrity jobs. Finally, scholars would do well to design and test the impact of leader integrity-based development interventions_-including trainings/workshops, surveys, coaching and other tools. 


\section{References}

1. Dineen, B. R., Lewicki, R. J., \& Tomlinson, E. (2006). Supervisory guidance and behavioral integrity: Relationships with employee citizenship and deviant behavior. Journal of Applied Psychology, 91, 622-635.

2. Graham, J., Haidt, J., \& Nosek, B. A. (2009). Liberals and conservatives rely on different sets of moral foundations. Journal of Personality and Social Psychology, Vol. 96, 1029-1046.

3. Leroy, H., Palanski, M., \& Simons, T. (2012, May). Authentic leadership and behavioral integrity as drivers of follower commitment and performance. Journal of Business Ethics, 107(3), 255-264.

4. Mayer, R. C., Davis, J. H., \& Schoorman, F. D. (1995). An integrative model of organizational trust. Academy of Management Review, 20, 709-734.

5. Simons, T. (2002). Behavioral integrity: The perceived alignment between managers' words and deeds as a research focus. Organization Science, 13, 18-35.

6. Simons, T. (2008). The integrity dividend: Leading by the power of your word. San Francisco: Jossey-Bass.

7. Simons, T., Liu, L. A., Friedman, R., \& Parks, J. M. (2007). Racial differences in sensitivity to behavioral integrity: Attitudinal consequences, in-group effects, and "trickle down" among black and non-black employees. Journal of Applied Psychology, 92(3), 650-665 (16p). 